\title{
The Effect of Mobile Indoor Air Cleaners on the Risk of Infection with SARS-CoV-2 in Surgical Examination and Treatment Rooms with Limited Ventilation Options
}

\author{
Oberst $\mathbf{M}^{1 *}, \operatorname{Klar} \mathbf{T}^{2}$ and Heinrich $\mathbf{A}^{2}$ \\ ${ }^{1}$ Clinic for Orthopedics, Trauma and Spinal Surgery, \\ Germany \\ ${ }^{2}$ Aalen University, Center for Optical Technologies, \\ Germany \\ *Corresponding author: Michael Oberst, Clinic \\ for Orthopedics, Trauma and Spinal Surgery, Ostalb \\ Klinikum Aalen, Im Kälblesrain 1, 73430 Aalen, Germany
}

Received: March 10, 2021; Accepted: April 20, 2021; Published: April 27, 2021

\begin{abstract}
Objective: Due to the airborne transmission of the Coronavirus Disease (Covid-19) via aerosols, we investigated the effect of a mobile air filter system in a surgical examination room.
\end{abstract}

Methods: A mobile indoor air cleaner (AP 90, DEMA-airtech, Germany) was run during regular surgical consulting hour in our outpatient's clinic. Aerosol concentration was measured by Fidas Frog fine dust monitoring system (Palas, Germany) by constantly recording $\mathrm{PM}_{1.0}, \mathrm{PM}_{2.5}, \mathrm{PM}_{4}, \mathrm{PM}_{10}$ and the total particle load $\mathrm{PM}_{\text {tot }}$

Results: The use of the air filter system led to a significant reduction of aerosols in the room despite the fact that there were various numbers of persons in the room constantly.

Conclusion: The use of a high efficiency air filtration device, especially in examination rooms with poor ventilation, e.g., lack of windows or local exhaust is recommendable.

Keywords: Covid-19; Aerosol; $\mathrm{PM}_{\mathrm{tot}}$; Ventilation

\section{Introduction}

Even though the ways in which SARS-CoV-2 is transmitted are not completely understood, droplet infection from airborne particles contaminated with the virus obviously play a decisive role in humanto-human transmission [1-3]. Different forms of emission (speaking, breathing, singing, coughing, sneezing, etc.) produce a wide range of particle sizes and transmit them to the surrounding air. Breathing and speaking produce particle cells of between $0.75 \mu \mathrm{m}$ and $1.1 \mu \mathrm{m}$, while coughing and sneezing produce much larger particles (larger than $5 \mu \mathrm{m}$ ) [4]. Particle distribution within a space also varies by particle size. Droplets $(>50 \mu \mathrm{m})$ fall to the floor relatively quickly, but aerosols $(<5 \mu \mathrm{m})$ can be detected in the air after several hours, and convection and other air movements can transport them several meters [3,5-7]. If they are inhaled, these particles can (depending on their size) penetrate deep into the respiratory tract, even reaching the alveoli $[2,5,8]$.

These particulate matter emissions are defined by the $\mathrm{PM}_{10}$ unit based on the National Ambient Air Quality Standards introduced by the U.S's Environmental Protection Agency in 1987. The 10 here does not stand for a sharp distinction at $10 \mu \mathrm{m}$ of aerodynamic diameter, but reflects an attempt to recreate the separation behavior in the upper respiratory tract: All particles with an aerodynamic diameter of less than $1 \mu \mathrm{m}$ are considered, while a certain percentage of larger particles are included. That percentage falls as particle size increases until $0 \%$ is reached at $15 \mu \mathrm{m}$. This is ultimately, where the $\mathrm{PM}_{10}$ designation comes from: $10 \mu \mathrm{m}$ is the exact halfway point in the size of particles considered. In 1997, $\mathrm{PM}_{2.5}$ was added to the guidelines. It refers to respirable (alveolar) particulate matter. The definition is analogous to $\mathrm{PM}_{10}$, but the weighting function is significantly steeper ( $100 \%$ weighting $<0.5 \mu \mathrm{m} ; 0 \%$ weighting $>3.5 \mu \mathrm{m} ; 50 \%$ weighting at about $2.5 \mu \mathrm{m}$ ) [9]. The regulations were further expanded to include $\mathrm{PM}_{1}$, which is analogous to $\mathrm{PM}_{2.5}$, but for $1 \mu \mathrm{m}$.

Given the transmission methods mentioned above, precautionary measures have been taken (or mandated) throughout Germany with the goal of reducing the risk of transmitting SARS-CoV-2 by reducing aerosol and droplet exposure. However, at this point German officials (Federal Environment Agency) doubt the effect of indoor air cleaners [10]. The German Society of "Hospital Hygiene sees" a high need for further studies" on the topic [11].

Therefore, by now it is especially important to increase air circulation in closed rooms and buildings by airing them regularly (Germany's "AHA+L" rule) [12]. This measure for potentially reducing viral load tied to airborne particles can scarcely be implemented in rooms with no windows (or at least not without major structural and technical interventions in ventilation systems).

In a previous trial, we had already noticed the positive effect of an indoor air cleaner on the concentration of airborne particles/aerosols in the ambient air of a consultation room without ventilation options [13], so we set up a repeat experiment under the same conditions but with improved, high-quality measurement technology and a mobile air cleaner with higher filtration capacity (see Material and Methods). The aim of the presented study was to find out which level of air replacement a device would need to achieve a relevant aerosol reduction and how the decline in air particles (half-life) is related to the device power level and the "personnel load" (public traffic during consultation hours).
Austin J Public Health Epidemiol - Volume 8 Issue 1 - 2021

ISSN : 2381-9014 | www.austinpublishing group.com

Oberst et al. (@) All rights are reserved
Citation: Oberst M, Klar T and Heinrich A. The Effect of Mobile Indoor Air Cleaners on the Risk of Infection with SARS-CoV-2 in Surgical Examination and Treatment Rooms with Limited Ventilation Options. Austin J Public Health Epidemiol. 2021; 8(1): 1094. 


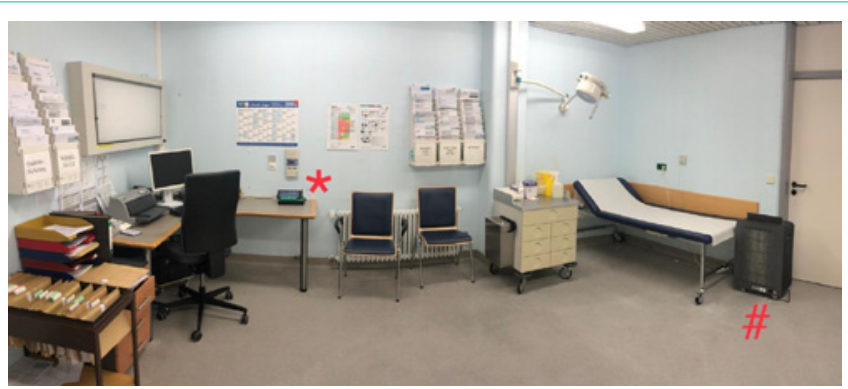

Figure 1: Surgical examination room in the outpatients clinic of the OstalbKlinikum Aalen without windows. *position of the dust monitoring system, "position of the mobile air cleaner (main door to the room on the backside of the camera view).

\section{Materials and Methods}

In Examination Room 2.148 (floor space of $21 \mathrm{~m}^{2}$, room volume of $52 \mathrm{~m}^{3}$ ) in our Clinic for Orthopedics, Trauma and Spinal Surgery (Figure 1), an ambient air filter device (DEMA-airtech, Stuttgart, Germany, Type AP-90) was deployed during routine surgical outpatients-clinic hours on $11 / 30 / 2020$. According to manufacturer information, the device's maximum filter capacity is $720 \mathrm{~m}^{3} / \mathrm{h}$. In addition to an activated carbon filter, a Class H13 HEPA (highefficiency particulate air) filter was installed (European Standard 1822, minimum filter efficiency $0.3 \mu \mathrm{g} / \mathrm{m}^{3} / \mathrm{h}$, efficiency $99.95 \%$ ). The filtered air is also treated with plasma and UV light, which the manufacturer says will kill $99 \%$ of viruses and bacteria (Guangdong Detection Centre of Microbiology, Report No. 2020SP8365R03E) after the filter, has eliminated airborne particles.

During consultation hours, ambient air aerosol and airborne particle load was continuously recorded for a total of four hours with the Fidas Frog Fine Dust Monitoring System (Palas GmbH, Karlsruhe, Germany). It continuously recorded particulate matter according to $\mathrm{PM}_{1.0}, \mathrm{PM}_{2.5}, \mathrm{PM}_{4}, \mathrm{PM}_{10}$ and the total particle load $\left(\mathrm{PM}_{\text {tot }}\right)$ (all measurements in $\mu \mathrm{g} / \mathrm{m}^{3}$ ). For the first two hours of consultation, the ambient air filter was switched off and the basic aerosol load in the room was merely recorded. After 120 minutes, the ambient air filter was run for seven minutes at top speed (blower at 4 of 4 ). The device was then operated for three more minutes at Level 3, then continuously for the rest of the consultation hours at Level 2.

For the entire period, the number of people in the room (doctor, receptionist, patients) and their length of stay were documented to the minute. Statistical evaluation was performed in Excel (Microsoft, Version 2020).

\section{Results}

In the observation period of four hours, 43 individual personal contacts took place in the consultation room on 11/30/2020 (total duration 240 minutes, multiple contacts may be named when individuals occupied the room at the same time). Consultation hours began at 7:30 AM, and the ambient air filter was started two hours later.

Table 1 shows the average particulate matter/airborne particle concentration for the various measurement parameters $\left(\mathrm{PM}_{1}, \mathrm{PM}_{2.5}\right.$, $\mathrm{PM}_{4}, \mathrm{PM}_{10}$, and $\left.\mathrm{PM}_{\text {tot }}\right)$ in the two hours before and after the ambient

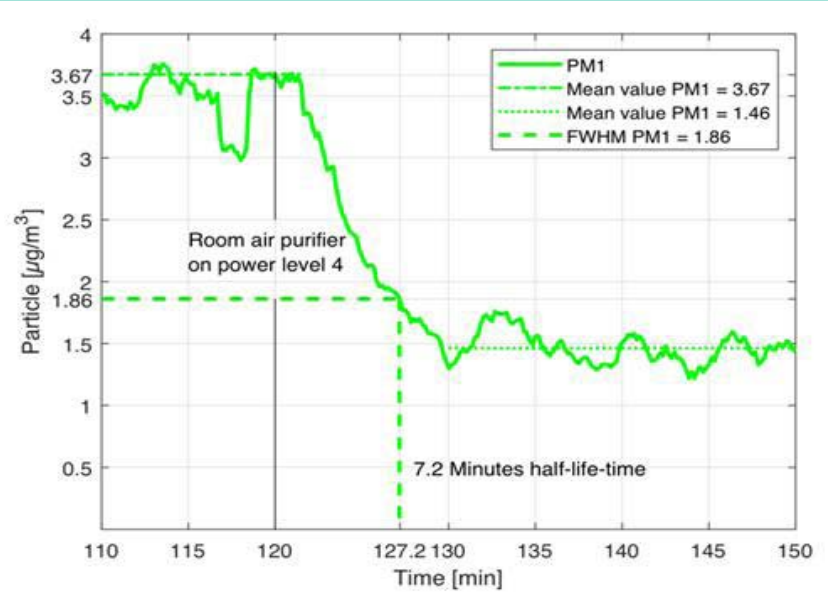

Figure 2: Aerosol concentration $\left(\mathrm{PM}_{1}\right)$ from minute 110 to 150 . Minute 120 marks the start of the air filter system at full power. Half-time reduction was achieved after 7.2 minutes.

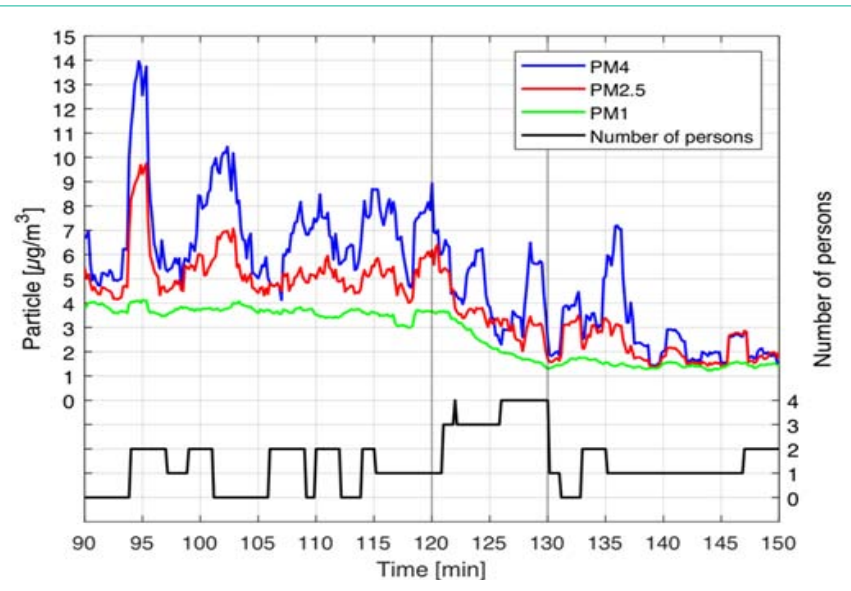

Figure 3: Particulate matter $\left(\mathrm{PM}_{1}, \mathrm{PM}_{25}, \mathrm{PM}_{4}\right)$ in $\mu \mathrm{g} / \mathrm{m}^{3}$ before filtering (90$120 \mathrm{~min}$ ), during high speed filtering (Level 4+3; 120-130 min) and under low level filtering (Level 2; $130-150 \mathrm{~min}$ ) in the outpatients clinic. Scale on the right: number of persons in the room.

Table 1: Average, standard deviation and median of measurement parameters (particulate matter in $\mu \mathrm{g} / \mathrm{m}^{3}$ ) with/without mobile air cleaner filtering and reduction of average in \%.

\begin{tabular}{|l|c|c|c|c|c|}
\hline & $\mathbf{P M}_{1,0}$ & $\mathbf{P M}_{2,5}$ & $\mathbf{P M}_{4}$ & $\mathbf{P M}_{10}$ & $\mathbf{P M}_{\text {tot }}$ \\
\hline WITHOUT filter & & & & & \\
\hline Average & 3,67 & 5,33 & 7,06 & 26,86 & 41,59 \\
\hline Standard deviation & 0,23 & 1,1 & 1,99 & 11,25 & 32,45 \\
\hline Median & 3,7 & 5,09 & 6,72 & 13,52 & 42,11 \\
\hline WITH filter & & & & & \\
\hline Average & 1,41 & 1,83 & 2,12 & 5,28 & 11,41 \\
\hline Standard deviation & 0,65 & 1,01 & 1,65 & 7,32 & 20,6 \\
\hline Median & 1,52 & 2,61 & 2,9 & 6,16 & 7,37 \\
\hline $\begin{array}{l}\text { Reduction of average with vs. without } \\
\text { filter }\end{array}$ & $61,5 \%$ & $65,6 \%$ & $69,9 \%$ & $80,3 \%$ & $72,5 \%$ \\
\hline
\end{tabular}

air filter was switched on. A clear reduction of the average value and median was observed for all particle sizes after the ambient air filter was started - each by more than $60 \%$ at least. 
A $50 \%$ reduction (half-life) in the $\mathrm{PM}_{1}$ particulate matter concentration was achieved with the seven minutes of full device power (Figure 2) even though there were relatively many people (34 ) in the room at that time (Figure 3). In the following three-minute phase at Level 3, aerosols continued to decline. Reducing filter power to Level 2 achieved a dynamic equilibrium, so that the aerosol concentration remained at the low level achieved, despite the fact that consultations continued normally.

\section{Discussion}

In the absence of causal therapy for Covid-19 and of a widely available SARS-CoV-2 vaccine, avoiding or reducing aerosol exposure is currently the most important measure for preventing infection. This reduction is achieved primarily by reducing contacts, social distancing, and especially by wearing masks that effectively cover the mouth and nose [14-16].

With respect to air exchange, previous studies have shown that closed rooms with public traffic and poor ventilation have much higher SARS-CoV-2 infection risk [17]. Kähler et al. [18] used an experimental setup under laboratory conditions (without public traffic) to show that mobile ambient air filters can reduce aerosol load to a minimal level within a very short period. Lelieveld et al. used a mathematical calculation to show a reduction in SARS-CoV-2 infection risk by a factor of 7-8 with "high-efficiency HEPA filtering" [19].

In another experimental study (classroom simulation), Bluyssen et al. showed that mobile ambient air filters with a HEPA function could achieve even better air exchange than various classical roomairing scenarios [20].

In a previous study, it was shown that mobile ambient air filters could clearly reduce aerosol load during routine surgical consultation hour operations [13]. However, this investigation's meaningfulness was lessened because of the reduced performance of the measuring instrument used. Additionally, the tested mobile air cleaner was of less filter capacity and was just run on automatic level during the whole measurement. The new investigation featured continuous, high-quality data recording that allowed a comprehensive picture to be captured. The half-life for the aerosol load reduction was just seven minutes at full device power, even though several people were in the room at the same time during that period (Figure 2 and 3). When consultation hours were continued and the device was set to a lower speed (because of the noise generated at top speed), the reduction in aerosol concentration achieved could be maintained indefinitely. In summary, the concentration of all particulate matter was reduced by almost $3 / 4$ in $\mathrm{PM}_{\text {tot }}$ and at least by more than $60 \%$ for the smallest particles $\left(\mathrm{PM}_{1}\right)$ respectively, when the air cleaner was used (Table 1). In this context we dispensed with calculation of $\mathrm{p}$-values because some data reached statistical significance $\left(\mathrm{PM}_{2.5}, \mathrm{PM}_{4}\right)$, some did not $\left(\mathrm{PM}_{1}\right.$, $\mathrm{PM}_{\text {tot }}$ ) due to inconstant normal distribution. However, this does not affect the expressiveness of our investigation. If the concentration of $\mathrm{PM}_{\text {tot }}$ is reduced by $72.5 \%$ with the use of a mobile air cleaner, the individual risk of infection of a disease transmitted by PM is reduced by $72.5 \%$ too, independently of the mathematical determination of statistical significance or not.

The continuous recording of dimension parameters and the documentation of the persons present in the room allowed the effect of persons in the room to be established. In the phase before the ambient air filter was switched on, there is an especially pronounced relationship between the number of persons in the room and the peaks in each size of aerosol particle. The more people were in the room, the higher the number of aerosols measured (Figure 3). This observation is limited by the fact that no exact mathematical relationship could be established. This is easily explained by the fact that while the presence of a person in the room was documented, the specific aerosol emissions by a given individual is dependent on a number of factors (type and duration of speech; coughing; sneezing; movement in the room; etc.), so that these emissions can never be standardized or predicted.

In our setup, the ambient air filter was turned down a level after seven minutes at top speed and down another level after three more minutes. This was due to the noise generated by the device. At full power, the device was simply too loud to continue consultation comfortably. Bluyssen et al. noted a similar effect [20]. Our results show that after an initial cleaning of the room's air, the number of aerosols can be kept constant at the level achieved even when the ambient air filter's fan speed is turned down to a level where the noise it produces is absolutely acceptable. This is a decisive point for future device regulation and control. In the brief periods between meetings with patients during which no one is in the room, an ambient air filter should be run at full power to simulate intensive ventilation.

Given a maximum device filter capacity of $720 \mathrm{~m}^{3} / \mathrm{h}$ at full power and a room volume of $52 \mathrm{~m}^{3}$, the air in a room can be completely replaced six times in one hour. This would fulfill german official's regulatories for indoor air ventilation [10] and means that 7.5 half-lives could theoretically be achieved. Assuming first-order elimination (elimination speed falls with aerosol concentration), the original concentration would be reduced by $87.5 \%$ after three halflives and by more than $99 \%$ after seven. Because the manufacturers of the ambient air filter claim that, more than $99.9 \%$ of viruses and bacteria are eliminated with UV light and plasma, the risk of aerosol transmission of pathogens (SARS-CoV-2) in the examination room described above would thus be practically eliminated.

\section{Conclusions}

A mobile ambient air filter can relevantly reduce the aerosol load in a closed room without ventilation capability under realworld conditions as represented by surgical consultation hours. This results in a corresponding infection risk potential reduction for a disease, such as SARS-CoV-2, that is transmitted by aerosols. In hospital examination and conference rooms whose design provide no ventilation capability, using mobile ambient air filters is advantageous given the current conditions of the COVID-19 pandemic.

\section{References}

1. Drossinos Y, Stilianakis NI. What aerosol physics tells us about airborne pathogen transmission? Aerosol Science and Technology? 2020; 54: 639-643.

2. Godri $P$, et al. COVID-19 vulnerability: the potential impact of genetic susceptibility and airborne transmission. Genomics. 2020; 14: 17 .

3. Lednicky JA, et al. Viable SARS-CoV-2 in the air of a hospital room with COVID-19 patients. Int J Infect Dis. 2020. 
4. Asadi S, et al. Aerosol emission and super emission during human speech increase with voice loudness. Scientific Reports. 2019; 9: 2348.

5. Morawska L, et al. Size distribution and sites of origin of droplets expelled from the human respiratory tract during expiratory activities. J Aerosol Sci. 2009; 40: 256-269.

6. Morawska L, Milton DK. Clinical Infectious Diseases, Invited Commentary; It Is Time to Address Airborne Transmission of Coronavirus Disease 2019 (COVID-19). 2020; 71: 2311-2313.

7. van Doremalen $\mathrm{N}$, et al. Aerosol and Surface Stability of SARSCoV-2 as Compared with SARS-CoV-1. N Engl J Med. 2020; 382: 1564-1567.

8. Umweltbundesamt. Emmission von Feinstaub der Partikelgroße $\mathrm{PM}_{2.5} .2020$.

9. Hainsch A. Ursachenanalyse der $\mathrm{PM}_{10}-\mathrm{Immission}_{\mathrm{In}}$ urbanen Gebieten am Beispiel der Stadt Berlin. Dissertation. TU Berlin. 2003.

10.Umweltbundesamt. 2020.

11. Exner M, Walger P, Gebel J, Schmithausen R, Kramer A and Engelhart S. Zum Einsatz von dezentralen mobilen Luftreinigungsgeräten im Rahmen der Prävention von COVID-19. 2020.

12.Beerheide R, Maibach-Nagel E. Pandemiekonzepte. Differenzierte Ansätze. Dtsch Aerztebl Int. 2020; 117: A2034-A2035.

13. Oberst $M$, Heinrich A. Effekt eines mobilen Raumluftfilters auf die Aerosol-Belastung in chirurgischen Untersuchungsräumen vor dem Hintergrund der Covid-19 Pandemie. Unfallchirurg. 2021.
14. Howard J, Huang A, Li Z, Tufekci Z, Zdimal V, Van der Westhuizen $\mathrm{H}$, et al. Face Masks Against COVID-19: An Evidence Review. Preprints. 2020: 2020040203.

15.Leung NHL, Chu DKW, Shiu EYC, Chan K-H, McDevitt JJ, Hau BJP, et al. Respiratory virus shedding in exhaled breath and efficacy of face masks. Nat. Med. 2020; 26: 676-680.

16. Maclntyre CR, Chughtai AA. A rapid systematic review of the efficacy of facemasks and respirators against coronaviruses and other respiratory transmissible viruses for the community, healthcare workers and sick patients. Int. J. Nurs. Stud. 2020; 108: 103629.

17.Somsen GA, van Rijn C, Kooij S, Bem RA, Bonn D. Small droplet aerosols in poorly ventilated spaces and SARS-CoV-2 transmission. Lancet Respir Med. 2020.

18.Kähler CJ, Fuchs T, Hain R. Can mobile indoor air cleaners effectively reduce an indirect risk of SARS-CoV-2 infection by aerosols. 2020 .

19.Lelieveld J, Helleis F, Borrmann S, et al. Model Calculations of Aerosol Transmission and Infection Risk of COVID-19 in Indoor Environments. Int J Environ Res Public Health. 2020; 17: 8114.

20.Bluyssen PM, Ortiz M, Zhang D. The effect of a mobile HEPA filter system on 'infectious' aerosols, sound and air velocity in the SenseLab. 2021. 